\title{
A BOCR and Fuzzy AHP method for identification and prioritization of carpet industry strategies
}

\author{
Hassan Rangriz $^{\mathrm{a}}$, Mahdi Hosseinpour ${ }^{\mathrm{b}}$ and Saeid Esmaeili ${ }^{\mathrm{b}^{*}}$
}

${ }^{a}$ Department of Management, University of Economical Science, Tehran, Iran

${ }^{b}$ M.A. Student of MBA, Kermanshah Science and Research Branch, Islamic Azad University, Kermanshah, Iran

\begin{tabular}{|c|c|}
\hline A R T I C L E I N F O & A B S T R A C T \\
\hline $\begin{array}{l}\text { Article history: } \\
\text { Received July 16, } 2012 \\
\text { Received in Revised form } \\
\text { August, 27, 2012 } \\
\text { Accepted } 20 \text { September } 2012 \\
\text { Available online } \\
\text { September } 252012 \\
\text { Keywords: } \\
\text { Fuzzy AHP } \\
\text { BOCR } \\
\text { SWOT } \\
\text { Carpet Industry }\end{array}$ & $\begin{array}{l}\text { Carpet is one of the most popular handcraft industries in Iran and it has created significant } \\
\text { number of jobs in various villages and small towns in this country. There are literally many } \\
\text { designs and plans introduced by Iranian carpet makers but during the past two decades, we have } \\
\text { seen an increasing competition mostly from other countries such as China, India, Pakistan, etc. } \\
\text { On the other hands, there are ongoing interests for membership of world trade organization } \\
\text { (WTO) and it is necessary to take the necessary actions. The proposed study of this paper uses } \\
\text { different mathematical techniques to consider different actions for changing threats to } \\
\text { opportunities, reducing unnecessary costs, increasing revenue and market share, etc. The } \\
\text { proposed model of this paper uses Fuzzy analytical hierarchy process (AHP), Benefits- } \\
\text { Opportunities-Costs-Risks (BOCR) method to detect possible benefit, risk and cost } \\
\text { components. We first setup all useful strategies and then using AHP prioritizes different }\end{array}$ \\
\hline
\end{tabular}

(c) 2012 Growing Science Ltd. All rights reserved.

\section{Introduction}

For years, hand-knitted carpet industry has been recognized as one of the most popular handicraft industries in Iran. The market was so attractive that other countries decided to jump to this business by creating the same types of Iranian made carpets with the same quality but cheaper prices. On the other hand, the recent advances of technology have created the opportunities for making industrybased carpet with relatively much lower prices. As a result, we could easily see a decline in market and an increase in competition as the results of new replacement products such as machine-knitted carpet, Moquette, stone, parquet, etc. As a result, it is necessary to setup a good strategic planning for building better opportunities for this industry.

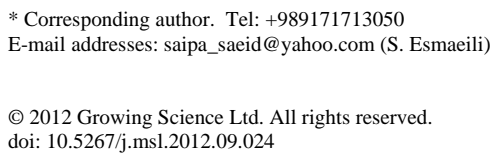


Strength, Weakness, Opportunity and Threats (SWOT) analysis is one of the most popular strategic planning methods. SWOT has many advantages and through its straightforward implementation, we can easily apply the method for different real-world applications. However, the method also suffers from various shortcomings such as lack of capability for ranking different alternatives. In fact, the SWOT method just compiles different strategies but does not determine the priority and benefits of the execution of each strategy. Therefore, we plan to use alternative method called BenefitsOpportunities-Costs-Risks (BOCR) method to detect possible benefit, risk and cost components. We first setup all useful strategies and then using AHP prioritizes different actions.

\section{Literature Review}

\subsection{AHP}

Analytic hierarchy process (AHP) introduced Saaty and nowadays is used as one of the broadest tools for solving the multi criteria decision-making (MCDM) problems. AHP has the ability of solving the unstructured problems in different dimensions of the field, which are studied by human being. Executing AHP has six main levels as follows (Saaty, 1980; Zahedi, 1986; Murtaza, 2003):

1. Defining the unstructured problem and declaring the aims and outputs clearly

2. Breaking the problem into a hierarchy structure with decision elements (criteria, alternatives, ...)

3. Making a comparison matrix using the pair comparisons by means of the decision elements

4. Estimating the weight of each comparison element

5. Inspecting the correctness of the pair comparisons matrix and also correctness of the judgment about the comparisons

6. Obtaining the point of each alternative using the obtained points and weights

\subsection{BOCR}

Every decision, in each level and area has some desirable and undesirable consequences. In decisionmaking for selecting and performing the projects, the positive consequences are considered as benefits and the negative consequences are considered as cost. These benefits and costs have equivalent monetary assessment unit, like dollar value. When for a project the index is: $\frac{\text { benefits }}{\text { costs }}>1$, the execution of the project is desirable and if comparing several projects is considered, the project with high rate of $\frac{\text { benefits }}{\text { costs }}$ is the most desirable project. The main problem in executing this method is that most of the time we cannot measure the benefits and costs with monetary unit for example increasing attention, increasing consent, creating jobs, etc. are the benefits, which cannot be measured by the monetary unit. In addition, some of the decision consequences may not be final. For example, executing a plan may not be accepted by the public opinions and be defeated. For this reason, in 2003 (Saaty \& Ezdmir, 2003) in spite of inspecting the weak points of AHP, showed that it is possible to add two factors of "opportunities" and "risks" to the above index called BOCR analysis. The introduced index is $\frac{B \times O}{C \times R}$ where $\mathrm{B}$ is the positive and certain consequences (benefits) and $\mathrm{O}$ is the positive and uncertain consequences (opportunities), $\mathrm{C}$ is the negative and certain consequences (costs) and $\mathrm{R}$ is the negative and uncertain consequences of executing decision. Saaty (2005) introduced four other formulas that make the weighting to the BOCR criteria possible. These formulas are as follows:

$$
\begin{aligned}
& P_{i}=b B_{i}+o O_{i}+c\left(\frac{1}{C_{i}}\right)+r\left(\frac{1}{R_{i}}\right) \\
& P_{i}=b B_{i}+o O_{i}+c\left(1-C_{i}\right)+r\left(1-R_{i}\right) \\
& P_{i}=b B_{i}+o O_{i}-c C_{i}-r R_{i}
\end{aligned}
$$


$P_{i}=B_{i}^{b} \times O_{i}^{o} \times\left(\frac{1}{C_{i}}\right)^{c} \times\left(\frac{1}{R_{i}}\right)^{r}$,

where, $\mathrm{R}_{\mathrm{i}}, \mathrm{C}_{\mathrm{i}}, \mathrm{O}_{\mathrm{i}}, \mathrm{B}_{\mathrm{i}}$ are total points of each alternative in risks criteria, costs, opportunities and benefits, respectively. In addition, $\mathrm{B}, \mathrm{O}, \mathrm{C}$, and $\mathrm{R}$ are considered as weights for the risks, costs, opportunities and benefits. $\mathrm{P}_{\mathrm{i}}$ is the priority or point of the $\mathrm{i}_{\text {th }}$ alternative.

\subsection{Fuzzy AHP}

Fuzziness is the general specification of the decision-making problems. A suitable decision-making problem shall have the ability to consider these specifications. Fuzzy modeling and questions (Klir \& Yuan, 1995) can accomplish changing the quantitative figures to qualitative numbers whenever experts provide uncertain feedbacks. Therefore, the traditional AHP method and following it pair comparisons, have no efficiency in the sophisticated problems (Cheng, 1999). Allocating fuzzy numbers to the qualitative amounts and components shall be performed by different methods. Each method has advantages and disadvantages. In this research, the centroid method that was developed by Yagar (1978) is used. In this method if $\mathrm{f}_{\mathrm{c}}(\mathrm{x})$ is considered as triangle fuzzy number membership function $\mathrm{C}=(\mathrm{p}, \mathrm{q}, \mathrm{s})$ its centroid is as follows $(\mathrm{Yu}, 2002)$ :

$R(c)=\frac{\int x f_{c}(x) d x}{\int f_{c}(x) d x}=\frac{\left[\frac{1}{q-p}\left(\frac{1}{3} q^{2}-\frac{1}{2} q^{2} p+\frac{1}{6} p^{2}\right)+\frac{1}{s-q}\left(\frac{1}{3} q^{2}-\frac{1}{2} q^{2} s+\frac{1}{6} s^{2}\right)\right]}{\left[\frac{1}{2}(s-p)\right]}$

and the value of each TFN would be calculated as:

$R(c)=\frac{1}{3}\left(p_{i}+q_{i}+s_{i}\right)$

\section{Methodology: FAHP model with BOCR}

In this part, we present the implementation of FAHP and BOCR for ranking the compiled strategies of carpet industry export in Iran. The proposed method considers the following levels,

Level 1: Establishment of a specialized committee of relevant people (carpet exporters, knitters, planners, experts of the carpet industry, experienced businessmen and ...) and description of the problem for them.

Level 2: Breaking the problems into hierarchy. In this level, four sub-branches (benefits, opportunities, costs and risks) are defined. Then final positive consequences, non-final positive consequences, final negative consequences and non-final negative consequences of executing all strategies are placed in the above sub-branches. This is performed by the experts' opinions and asking this question: "which are the final, non-final, negative and positive consequences of executing strategies?”

Level 3: Preparing questionnaire. In this level, some questionnaires are prepared and through it the pairwise comparisons of the importance degree are placed between the main four sub-branches at first and then it is asked from each expert to allocate his/her ideal weight about the importance degree of each lower level sub-branch.

Level 4: Calculations of importance weight

In this level, first we are speaking about the importance degree of the benefits, costs, opportunities and risks towards each other. We allocate number 1 to the word "equivalent", number 3 to "rather 
more important”, number 5 to “more important”, number 7 to "very important”, number 9 to “very very important". For example if the benefits are more important than opportunities, we allocate 1/7 for the opportunities/benefits. Then we find the importance weight of each sub-branch by normalization. We do this for the answered questionnaires and we consider their average as final weight of the main four sub-branches. For the lower sub-branches, because they are many and have less importance, the direct weighting is used instead of pair comparisons. Like the previous part, we find the weight of each lower level sub-branch using the average method for the weights acquired from the questionnaires.

Level 5: Assigning point to each strategy in each sub-branch: in this level, for each strategy in each sub-branch we can consider a point. This point can be a word point (very high, high, average, low, and very low). In this case the numeral amounts (1, 3, 5, 7 and 9) shall be allocated to them, respectively. In addition, these points can be like triangle fuzzy numbers (if the experts are familiar with the fuzzy numbers). In the first case, we find the average of the allocated points for each strategy. In the second case, instead of calculating the average of the points we use the fuzzy calculations. For example, if following numbers are acquired from five experts, calculating the final point of the considered criteria for the strategy under discussion is as follows:

$(1,2,3)(1,2,3)(1,2,3)(1,1,2)(2,3,4) \rightarrow\left\{\begin{array}{l}p_{i}=(1 \times 1 \times 1 \times 2 \times 1)^{\frac{1}{5}}=1.15 \\ q_{i}=(2 \times 2 \times 1 \times 3 \times 2)^{\frac{1}{5}}=1.89 \\ s_{i}=(3 \times 3 \times 2 \times 4 \times 3)^{\frac{1}{5}}=2.93\end{array}\right.$

or $C_{i}=\left(p_{i}, q_{i}, s_{i}\right)=(1.15,1.89,2.93)$ and at the end the point of that strategy in that sub-branch is as follows:

$R_{i}(c)=\frac{1}{3}\left(p_{i}+q_{i}+s_{i}\right)+\frac{1}{3}(1.15+1.09+2.93)=1.99$

Level 6: Calculating the final point of each strategy and ranking: in this level, we multiply the acquired point for each strategy in relation to the sub-branches in the weight of the sub-branches. We perform the related calculations for acquiring total points of each strategy and at the end its priority degree, depending to the used formula (Eqs. 1-4)

\section{Application of model in exporting Iran's hand-knitted carpet on the threshold of the globalization}

In this part, we discuss details of the compiled strategies for exporting Iran's hand-knitted carpet. Some of the compiled strategies are from one material, innately so we can merge them. In fact, the main strategies under discussion are as follows;

A. Joining the studies of the young experts with master craftsmen in presenting high-grade productions, adjusting to the interest and needs of the world customers

B. Emphasizing on quality, beauty and durability of the Iranian carpet

C. Maintaining the competition ability in quality, cost price, technology and production diversity

D. Increasing the production capacity for decreasing the cost price of the product

E. Establishing research centers for innovation in the field of marketing researches and production

F. Increasing marketing activities, internet marketing researches and advertisements for competing with the internet exporters

G. Teaching the last techniques of the carpet weaving to the carpet weavers 
Fig. 1 shows the relationship among different strategies and consequences of the project. In fact, all the consequences for all the strategies shall be measured.

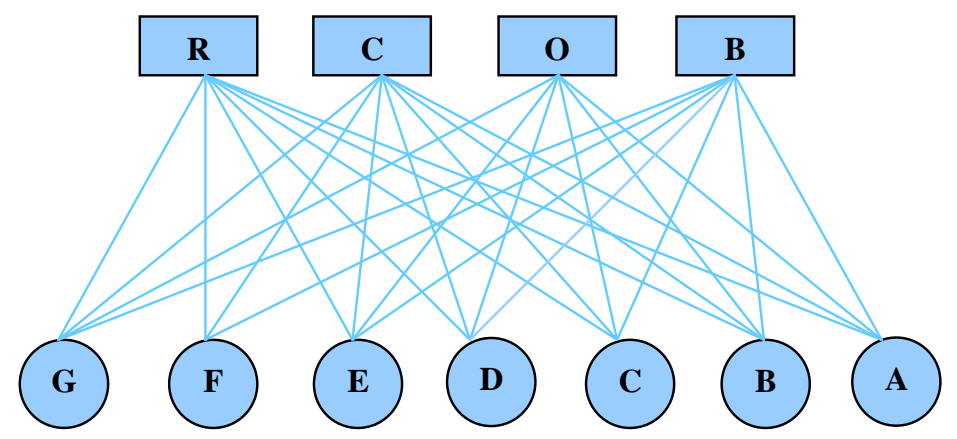

Fig.1. Relation between strategies and consequences of the project

After inspecting the questionnaires, following matters are acquired as the consequences for executing the strategies. Next, we acquire the weights resulted from the pairwise comparisons among benefits, opportunities, costs and risks. We avoid showing the calculations of acquiring the weights of the subbranches, because its steps have been describes. Table 1 shows the abstract of the information acquired from questionnaires. In the left column, the main sub-branches and their weights are written. The second column shows the second sub-branch with the weight and importance of each level two sub-branch.

The next columns show the average of the points that experts gave in the effect of executing the strategies in the acquired criteria. These amounts were in the shape of word amounts and then they were changed. For example, in the strategy column " $\mathrm{A}$ " and raw "production increase" we see number $4 / 2$. This means that the average grade of the strategy " $A$ " is $4 / 2$ from the experts' point of view for increasing the production. It means that executing it, has average effect on production increase. Table 1 shows details of priorities for executing various strategies using different formulas.

\section{Table 1}

The weight of different criteria using various methods

\begin{tabular}{|c|c|c|c|c|c|c|c|c|c|}
\hline Main Criteria & Sub Criteria & Criteria & $\mathrm{A}$ & $\mathrm{B}$ & $\mathrm{C}$ & $\mathrm{D}$ & $\mathrm{E}$ & $\mathrm{F}$ & G \\
\hline \multirow{7}{*}{ Benefits (0.34) } & \multirow{3}{*}{$\begin{array}{l}\text { Financial } \\
0.43\end{array}$} & Increasing production & 4.2 & 3.6 & 7.9 & 9 & 6.6 & 2.3 & 8.3 \\
\hline & & Decreasing costs & 7.6 & 1.7 & 7.8 & 8.1 & 5.8 & 1.8 & 8.5 \\
\hline & & Income creating & 6.7 & 6.5 & 6.7 & 9 & 4.7 & 5.6 & 7.6 \\
\hline & \multirow{4}{*}{$\begin{array}{l}\text { Non-financial } \\
0.57\end{array}$} & Job creating & 6.5 & 4.3 & 7.3 & 7.8 & 5.3 & 4.5 & 8.1 \\
\hline & & Increasing job consent & 8.3 & 7.8 & 5.9 & 6.8 & 7.6 & 7.8 & 7.4 \\
\hline & & Decreasing dependence to the oil export & 5.5 & 4.3 & 5.8 & 5.5 & 3.9 & 4.3 & 5 \\
\hline & & Maintaining and expanding national handicrafts & 4.3 & 4.6 & 7.3 & 5.3 & 7.6 & 3.2 & 8.1 \\
\hline \multirow{5}{*}{$\begin{array}{l}\text { Opportunities } \\
(0.11)\end{array}$} & \multirow{3}{*}{$\begin{array}{l}\text { Technology } \\
0.35\end{array}$} & Changing traditional structure to modern & 8.6 & 5.4 & 7.9 & 7.6 & 8.2 & 7.6 & 8.2 \\
\hline & & Entering carpet new technology & 7.5 & 3.8 & 8.6 & 8.4 & 8 & 4.4 & 8.1 \\
\hline & & Using internet world network & 7.5 & 6.9 & 2.3 & 4.4 & 7.1 & 9 & 7.9 \\
\hline & \multirow{2}{*}{$\begin{array}{l}\text { Communications } \\
0.65\end{array}$} & Developing international communications & 4.9 & 1.4 & 2.5 & 3.6 & 6.5 & 8.3 & 7.5 \\
\hline & & Increasing importance of Iran in the world market & 7.5 & 6.5 & 5.6 & 6.9 & 4.9 & 5.2 & 5.9 \\
\hline \multirow{5}{*}{ Costs } & \multirow{3}{*}{ financial } & Training costs & 7.3 & 4.8 & 7.6 & 8.2 & 8.1 & 3.4 & 7.2 \\
\hline & & Development costs & 7.2 & 3.9 & 7.5 & 7.9 & 7.8 & 2.9 & 7.2 \\
\hline & & Executive costs & 6.9 & 5.4 & 6.6 & 5.5 & 6.1 & 4.5 & 8.1 \\
\hline & \multirow{2}{*}{ temporal } & Execution time & 8.1 & 2.9 & 7.6 & 5.4 & 7.7 & 1.8 & 7.2 \\
\hline & & Utilization time & 8.1 & 3.8 & 8 & 6.1 & 8.1 & 3.3 & 4.1 \\
\hline \multirow{6}{*}{ Risks } & \multirow{3}{*}{$\begin{array}{l}\text { Executive } \\
\text { limitations }\end{array}$} & Financial limitations & 8.5 & 4.4 & 7.9 & 7.0 & 6.8 & 1.2 & 6.2 \\
\hline & & Boycotts & 2.2 & 4.5 & 2.1 & 7.7 & 4.4 & 1.8 & 3.2 \\
\hline & & Other limitations & 6.5 & 6.3 & 4.8 & 6.9 & 5.3 & 1.6 & 7 \\
\hline & \multirow{3}{*}{$\begin{array}{l}\text { Breaking the } \\
\text { strategy }\end{array}$} & Executing the strategies unsuccessfully & 1.8 & 1.5 & 2.2 & 4.5 & 1.9 & 1.5 & 1.3 \\
\hline & & Replacing other goods & 1.3 & 2.1 & 3.5 & 4.3 & 1.8 & 1.4 & 1.2 \\
\hline & & Increasing or continuing the economic world crisis & 2.8 & 3.8 & 2.8 & 3.8 & 3.3 & 3.1 & 2.2 \\
\hline
\end{tabular}


2874

Table 2 demonstrates details of relative weights for all alternatives based on four different formulas explained earlier.

Table 2

Details ranking various groups

\begin{tabular}{lccccccc}
\hline \multirow{2}{*}{ Each criteria and formula } & \multicolumn{6}{c}{ Sum of weights for each strategy in each criteria and formula } \\
\cline { 2 - 8 } & $\mathrm{A}$ & $\mathrm{B}$ & $\mathrm{C}$ & $\mathrm{D}$ & $\mathrm{E}$ & $\mathrm{F}$ & $\mathrm{G}$ \\
\hline $\mathrm{B}(0.34)$ & 20.210 & 19.717 & 21.441 & 21.909 & 18.126 & 17.566 & 22.812 \\
$\mathrm{O}(0.11)$ & 13.450 & 12.615 & 17.922 & 18.146 & 10.035 & 9.763 & 21.355 \\
$\mathrm{C}(0.37)$ & 8.641 & 9.714 & 8.213 & 6.331 & 10.855 & 12.219 & 5.918 \\
$\mathrm{R}(0.18)$ & 13.367 & 12.918 & 8.751 & 17.445 & 9.193 & 12.183 & 10.920 \\
\hline Formula 1 & 3.3141 & 2.9791 & 4.7116 & 4.8913 & 2.3623 & 1.9345 & 5.0014 \\
Formula 2 & 0.6194 & 0.5982 & 0.6563 & 0.6976 & 0.5817 & 0.5345 & 0.7113 \\
Formula 3 & 0.04310 & 0.02918 & 0.0954 & 0.1467 & -0.0151 & -0.0189 & 0.1619 \\
Formula 4 & 1.5612 & 1.1192 & 1.8959 & 2.0736 & 1.0823 & 1.0239 & 2.2149 \\
\hline
\end{tabular}

According to the acquired points resulted from each formula, we reach to the similar results. In fact, the order of the strategies based on the acquired points is as follows;

G-D-C-A-B-E-F

\section{Summation of the Results}

In this article, the compiled strategies for exporting the Iran's carpet industry were studied. Since the compiled strategies are acquired from SWOT analysis method, therefore; there is no ranking for them. In this research, we have tried to rank the strategies to increase efficiency. Using BOCR analysis and fuzzy AHP helped us maintain the fuzzy decision-making and inspecting different aspects of executing the compiled strategies. Using the mentioned analysis, we emphasized on increasing the efficiency and exploiting them to maintain the fuzzy decision-making.

\section{Acknowledgment}

The authors would like to thank the experts who cordially participated in this survey.

\section{References}

Cheng, C.H. (1999). Evaluating weapon systems using ranking fuzzy numbers. Fuzzy Sets and Systems, 107, 25-35.

Klir, G.I., \& Yuan, B. (1995). Fuzzy Sets and Fuzzy Logic Theory and Applications. London: Prentice-Hall.

Murtaza, M.B. (2003). Fuzzy-AHP application to country risk assessment. American Business Review, 21 (2), 109-116.

Saaty, T.L., \& Ozdemir, M. (2003). Negative priorities in the analytic hierarchy process. Mathematical and Computer Modelling, 37, 1063-1075.

Saaty, T.L. (1980). The Analytic Hierarchy Process. New York: McGraw-Hill.

Yagar, R.R. (1978). On a general class of fuzzy connective. Fuzzy Sets and Systems, 4, 235-242.

Yu, C.S. (2002). A GP-AHP method for solving group decision-making fuzzy AHP problems. Computers and Operations Research, 29, 1969-2001.

Zahedi, F. (1986). The analytic hierarchy process- a survey of the method and its applications. Interfaces, 16, 96-108. 